\title{
AC 2007-2930: A SCHOLARSHIP RECRUITMENT AND SELECTION STRATEGY THAT SUCCESSFULLY ATTRACTS DIVERSE AND ACADEMICALLY TALENTED FRESHMEN
}

\section{Chris Papadopoulos, University of Wisconsin -Milwaukee}

Chris Papadopoulos is Assistant Professor of Civil Engineering and Mechanics at the University of Wisconsin-Milwaukee. He is the PI of the UWM Computer Science, Engineering and Mathematics $>$ Scholarship Program. His teaching and research interests are in engineeing mechanics, structural stability, engineering ethics, and engineering education. He is a recipient of the 2006 Ferdinand P. Beer and E. Russell Johnston, Jr. Outstanding New Mechanics Educator Award through the Mechanics Division of ASEE.

\section{Karen Brucks, University of Wisconsin-Milwaukee}

Karen M Brucks is Associate Professor of Mathematical Sciences at the University of Wisconsin Milwaukee. Her research interests are in Low Dimensional Dynamical Systems. She is a former Fulbright Scholar will be teaching at the NSF funded Summer Mathematics Program to held at Carleton College in Summer 2007. She is Co-PI of the UWM Computer Science, Engineering and Mathematics Scholarship Program.

Eric Key, University of Wisconsin-Milwaukee

Eric Key is a Professor of Mathematical Sciences at the University of Wisconsin-Milwaukee. He is a Co-PI for the UWM Computer Science, Engineering and Mathematics Scholarship Program and a Senior Scientist for the NSF supported Milwaukee Mathematics Partnership, as well as the Assistant Chairperson of the Mathematical Sciences Department and co-director of UWM's Actuarial Science program. His teaching and research interests are in probability theory and linear algebra.

\section{Ethan Munson, University of Wisconsin-Milwaukee}

Ethan Munson is Associate Professor, Department of Electrical Engineering and Computer Science at the University of Wisconsin-Milwaukee. He is co-PI of the UWM Computer Science, Engineering and Mathematics Scholarship Program. His teaching and research interests are in document engineering, software engineering and human-computer interaction. He is chair of ACM SIGWEB, the Special Interest Group on Hypertext, Hypermedia and the Web.

\section{K Vairavan, University of Wisconsin-Milwaukee}

K. Vairavan is a Professor of Electrical Engineering and Computer Science and a Co-Director of the Medical Informatics PhD program at the University of Wisconsin-Miwaukee. His technical interests include distributed systems, software complexity, medical informatics, and computer science and engineering education. 


\title{
A Scholarship Recruitment and Selection Strategy that Successfully Attracts Diverse and Academically Talented Freshmen
}

\begin{abstract}
We describe recruitment and selection procedures of the Computer Science, Engineering, and Mathematics Scholarship (CSEMS) Program at the University of Wisconsin-Milwaukee that are designed to attract students who are academically talented, financially needy, and diverse. In particular, we address the possible exclusion of underrepresented minority students that could result if standardized test scores are used indiscriminately as metrics of student performance in both recruitment and selection procedures. We describe a "conditional award" process that enables students whose calculus placement is moderately below calculus to competitively apply for and receive scholarships; awards to such students are activated on the condition that they attempt to attain calculus placement prior to matriculation. We present data that demonstrate moderate effectiveness of these methods in fostering diversity among our scholars and reasonably encouraging retention and estimated graduation rates. We discuss areas of improvement for future program years, such as forging new partnerships with local Project Lead The Way high schools to recruit higher numbers of females and minorities, and developing new mentoring opportunities to reduce attrition, especially among underrepresented minority students.
\end{abstract}

\section{Introduction}

The Computer Science, Engineering, and Mathematics Scholarship (CSEMS) Program was authorized by Congress as part of the American Competitiveness and Workforce Act of 1998. It is administered by the National Science Foundation's Division of Undergraduate Education (DUE). The program was modified in 2004 and is now known as the Scholarships in Science, Technology, Engineering, and Mathematics (S-STEM) Program. The CSEMS Program supports academically talented students, financially needy students for study in the "targeted disciplines" of computer science, engineering, and mathematics; the S-STEM program will additionally support study in other natural sciences. Although metrics of financial need are established by the federal government, participating institutions interpret thresholds for academic merit and financial need based on local circumstances. In addition to supporting students with financial need, the CSEMS and S-STEM programs broadly aim to increase the number of students particularly traditionally underrepresented students - who choose study, attain degrees, and ultimately seek employment in the STEM disciplines.

In 2002, the College of Engineering and Applied Science (CEAS) and the College of Letters and Science (L\&S) at the University of Wisconsin-Milwaukee (UWM) received a grant to establish a CSEMS Program. Our program was designed to respond to the following circumstances: (1) only about $30 \%$ of incoming freshmen in the targeted disciplines (engineering, computer science, and mathematics) are placed at calculus; (2) many students take courses out of sequence (e.g. approximately $30 \%$ of students in "sophomore" Dynamics are seniors); and (3) being financially needy, approximately $75 \%$ of UWM students work at least 20 hours per week to support their 
studies, and many of these work full time. Consequently, less than $40 \%$ of freshmen entering CEAS graduate with a degree from $\mathrm{CEAS}^{1,4,5}$; for those who do graduate, the average time to graduation is 6.8 years $^{1}$ [1]. Recognizing these circumstances as root issues that must be addressed at the beginning of a student's program of study, we determined that a freshman program was best suited to serve our students.

We crafted our program to support entering freshmen for up to two years, providing scholarships fixed at $\$ 3000$ per student per year (the maximum award value allowed by NSF at the time was $\$ 3125$ per student per year). The relative value of this scholarship was roughly $75 \%$ of tuition at the inception of the program, and has declined to approximately $50 \%$ of tuition today. The Program delivers the scholarship in increments of $\$ 1500$ per semester; continuation of the scholarship from semester to semester is contingent upon satisfactory academic performance. Students are also provided with dedicated faculty and staff mentoring, monthly seminars, tutoring opportunities, and other student support services. The UWM program provides study in Engineering (Civil, Mechanical, Electrical, Manufacturing \& Industrial, Materials), Computer Science, and Mathematical Sciences.

The budget allowed us to plan for three cohorts of approximately 20 students each, with the first cohort admitted in Fall 2003. However, in anticipation that freshman recruitment would be difficult, and yet wanting to develop the program as quickly as possible, we built in a contingency to admit students as sophomores if spaces remained after awards for entering freshmen were offered. We exercised this contingency for students entering during the first two program years (entering Fall 2003 and Fall 2004), but not during the third (Fall 2005). A smaller fourth cohort of entering freshmen was admitted (Fall 2006) using carry-over funds resulting from attrition and a contribution of $\$ 20,000$ from CEAS.

Because our program admits freshmen, recruitment and student selection are especially critical and challenging program elements. Identifying, attracting, and selecting a diverse cohort of students who meet the dual profile of demonstrated academic merit and financial need involves designing and implementing an integrated recruitment and selection plan that ensures that underrepresented students are attracted and can be competitive, while casting a small enough net to avoid soliciting applications from students who are unlikely to be successful in the program.

A dominant portion of our overall efforts in the early years of the program were devoted to learning more about recruitment issues and developing annual adjustments to respond to trends that we observed. In what follows, we discuss what we learned in the process and how adjustments were made over time. Due to the intended freshman emphasis of our program, and for simplicity, we will focus on aspects of our program that directly bear on freshman recruitment, selection, and related matters.

A primary success of our program was the development of a "conditional award" process in which applicants whose math placement is at pre-calculus (College Algebra and/or Trigonometry) have a competitive chance to be awarded a scholarship. Awards are then given to students with pre-calculus placement on the condition that a satisfactory attempt is made to gain calculus placement prior to matriculation. As a result, whereas $78 \%$ of CSEMS awardees are initially calculus-ready, $97 \%$ are calculus-ready by the time of matriculation in the Fall. This is a 
great improvement over the barely $30 \%$ calculus-placement rate of all new freshmen entering the targeted disciplines at UWM. We also show that 1-year and 2-year retention, as well as projected graduation rates, exceed the ambient levels in the targeted disciplinary areas, even when compared with rates derived from students who matriculate with similar profile as the CSEMS scholars.

\section{Background Data}

To place the UWM CSEMS Program in context, we provide some baseline data for students in the targeted disciplines at UWM. We remind the reader that students in engineering and computer science are in the College of Engineering and Applied Science (CEAS) and students in mathematical sciences are in the College of Letters \& Science (L\&S). In certain instances, data is available only for students in CEAS; since the vast majority of CSEMS students and the vast majority of all students in the targeted disciplines are in CEAS, the CEAS data suffices to provide reasonable background data.

Table 1 provides data for total enrollment and enrollment of new students (includes both new freshmen and new transfers [2]) in the targeted disciplines over the last three years. From this data, it can be calculated that over this period females and underrepresented minorities comprise, on average, $10.6 \%$ and $14.5 \%$ of new student enrollees, respectively. We note that the University of Wisconsin System includes students with ancestry from Laos, Vietnam, and Cambodia as "underrepresented minorities", and these students are counted in general enrollment and degree data presented in this document ${ }^{10}$. These students typically match the academic and economic profile of most underrepresented students in the targeted disciplines.

\begin{tabular}{|l|rrrr|rrrr|rrr|r|}
\hline Table 1. Total and New Student Undergraduate Enrollment in the Targeted Disciplines 2003-04, 2004-05, and 2005-06. \\
\hline Discipline & \multicolumn{3}{|c|}{$2003-04$} & \multicolumn{3}{c|}{$2004-05$} & \multicolumn{5}{|c|}{$2005-06$} \\
& Fem & URM & NS & TE & Fem & URM & NS & TE & Fem & URM & NS & TE \\
\hline Civil Eng. & 14 & 5 & 72 & 234 & 4 & 4 & 52 & 250 & 10 & 4 & 64 & 266 \\
Electrical Eng. & 2 & 13 & 62 & 297 & 3 & 10 & 65 & 307 & 3 & 6 & 56 & 290 \\
Industrial Eng. & 0 & 1 & 5 & 39 & 0 & 1 & 13 & 44 & 1 & 0 & 7 & 44 \\
Materials Eng. & 0 & 0 & 2 & 14 & 0 & 0 & 4 & 11 & 0 & 0 & 6 & 17 \\
Mechanical Eng. & 6 & 17 & 138 & 413 & 2 & 9 & 116 & 422 & 5 & 11 & 127 & 442 \\
Computer Sci. & 22 & 41 & 176 & 517 & 10 & 39 & 136 & 479 & 9 & 25 & 108 & 441 \\
Mathematical Sci. & 15 & 4 & 39 & 135 & 20 & 3 & 57 & 156 & 18 & 5 & 50 & 174 \\
\hline Total & 59 & 81 & 494 & 1649 & 39 & 66 & 443 & 1669 & 46 & 51 & 418 & 1674 \\
Total Rates (\%) & 11.9 & 16.3 & 100 & -- & 8.8 & 14.9 & 100 & -- & 11.0 & 12.2 & 100 & -- \\
\hline Fem = new females, URM $=$ new underrepresented minorities, NS = total new students, TE = total enrollment. \\
\hline
\end{tabular}

According to the Engineering Student Services Office, 27.2\% of entering freshmen in CEAS matriculated with calculus placement ${ }^{4}$. The calculus placement rates for females and underrepresented minority students are $26.7 \%$ and $8.1 \%$, respectively ${ }^{4}$. As discussed in the introduction, this low calculus placement rate was one factor that fundamentally influenced the design of our CSEMS Program. In Section 4 (Table 3), we present data to demonstrate that CSEMS students matriculate with calculus placement at an overall rate of $97 \%$, including $88 \%$ for conditional awardees (i.e. awardees who were not initially calculus-placed). 
According to the University's Office of Assessment and Institutional Research, the 1-year and 2year retention rates in CEAS - i.e. the percentage of entering freshmen in CEAS who remain enrolled in CEAS at the beginning of each subsequent Fall semester - are approximately $60 \%$ and $45 \%$, respectively ${ }^{7}$ [3]. According to the Engineering Student Services Office, the generally accepted graduation in CEAS - i.e. the percentage of entering freshmen in CEAS who graduate with a degree from CEAS - is about $30 \%{ }^{4}$. A recent data query revealed that $27.8 \%$ of freshmen entering in Fall 1999 graduated with a degree in CEAS ${ }^{8}$. As we present in the next section, we estimate that the overall graduation rate of CSEMS students will be approximately $61.3 \%$. This is clearly much higher than the ambient rate in CEAS, but this comparison is not necessarily appropriate because the average entering CSEMS freshman has a stronger academic profile than the average entering freshman in CEAS. In order to provide a better comparison against which to measure the success of the CSEMS Program, we extracted a subset of comparable students from the class entering in Fall 1999. We demonstrate that the CEAS graduation rate of students in this comparison group is $52.9 \%{ }^{5}$. Thus, it is clear that the CSEMS Program has a positive impact.

\section{Recruitment of Students: Challenges Presented by Using Standardized Data}

The ideal CSEMS student meets the following two basic criteria:

- Calculus placement by the time of matriculation (defined by the UW System Math Placement Test)

- Expected Family Contribution $+\$ 3000<$ Estimated Cost of Attendance.

In addition, the program aims to admit a diverse cohort of students that includes significant numbers of females and underrepresented minorities. Students who meet this profile are difficult to recruit, and constitute a very small population of students in CEAS. For example, a recent data query conducted by the University's Office of Financial Aid revealed that of the 135 freshmen entering CEAS for Fall 2006 who had achieved calculus placement and had applied for federal aid, only $30(22.2 \%)$ matched this profile ${ }^{8}$. Of these 30 students, only 2 were female and 1 was an underrepresented minority ${ }^{8}$.

Beginning with our second recruitment cycle, we attempted to systematically identify and contact prospective applicants who we estimated would match our profile. We purchased a set of student records from Educational Opportunity Service (EOS) that were used to develop a direct mailing. We selected students who met several baseline criteria (from a discrete menu of options), including estimated family income below $\$ 50,000$, completion of three years of high school math and science, overall high school GPA of at least 2.50, and resident of Wisconsin.

In addition to the baseline criteria, we selected students based on ACT Math score. By studying the relationship between ACT Math score and Math Placement of students at UWM, we determined that students must score at least 28 on the ACT in order to have a reasonable (42\%) chance of attaining calculus placement. We therefore selected students at or above this score threshold. We were struck by the following result: this query generated a list of 525 students but only 2 were identified as African American, and only 6 as Hispanic. 
Realizing that this essentially eliminated underrepresented minorities from our mailing, we ran a second query with the same baseline criteria, and the further criteria of Math ACT score 24-27 and identification as non-white. According to our data, students in this score range have about $8 \%$ chance of earning calculus placement. This query identified 99 additional students. To gain further insight into this exclusion of minority students, we obtained data from the Wisconsin Department of Public Instruction that revealed the following: in Wisconsin, the average Math ACT scores for White Caucasians, African Americans, and Hispanics are 23.2, 17.2, and 20.0, respectively ${ }^{11}$.

Given (1) the severity with which these disparities exclude underrepresented minority students, (2) our overall dissemination of materials was widespread and not restricted to any specific population of students, and (3) our selection process was independent of race and gender, we justified mailing information to all students with scores of at least 28 and to only underrepresented minorities with scores in the range 24-27.

Table 2 provides application and entry data for the Program's four recruitment cycles. Overall, $16.3 \%$ of applicants and $13.1 \%$ of entering students are underrepresented minorities; $13.1 \%$ of applicants and $12.5 \%$ of entering students are female. These proportions are comparable to the overall population of students entering CEAS (see Table 1, Section 2), but they far exceed the proportions of underrepresented freshmen in CEAS who also meet the criteria of the CSEMS Program (see beginning of Section 3).

\begin{tabular}{|l|r|r|r|r|r|r|r|r|r|r|r|}
\hline Table 2. Application History of CSEMS Students at UWM. \\
\hline & Fall 2003 & Fall 2004 & Fall 2005 & \multicolumn{2}{|c|}{ Fall 2006 } & \multicolumn{2}{|c|}{ Total } \\
\hline & App & Ent & App & Ent & App & Ent & App & Ent & App & Ent \\
\hline Total & 41 & 12 & 41 & 20 & 46 & 23 & 25 & 9 & 153 & 64 \\
\hline URM & 4 & 1 & 7 & 3 & 9 & 4 & 5 & 1 & 25 & 9 \\
\hline$\%$ URM & $9.8 \%$ & $8.3 \%$ & $17.1 \%$ & $15.0 \%$ & $19.6 \%$ & $17.4 \%$ & $20.0 \%$ & $11.1 \%$ & $16.3 \%$ & $14.1 \%$ \\
\hline Fem & 3 & 1 & 4 & 1 & 7 & 4 & 6 & 2 & 20 & 8 \\
\hline$\%$ Fem & $7.3 \%$ & $8.3 \%$ & $9.8 \%$ & $5.0 \%$ & $15.2 \%$ & $17.4 \%$ & $24.0 \%$ & $22.2 \%$ & $13.1 \%$ & $12.5 \%$ \\
\hline $\begin{array}{l}\text { URM = underrepresented minority; Fem = female } \\
\text { App: Total number of applicants; Ent = Number of students who entered program }\end{array}$
\end{tabular}

We believe that targeting students partially by ethnic identity in the direct mail process is at least partly responsible for this reasonable success, especially considering that the diversity of the applicants and entering students increased beginning with the Fall 2004 cohort, the point at which the procedures were implemented. However, we have since discovered that some reviewers and campus officials discourage this and other approaches that directly target students based on race, even if selection criteria are race-independent. In Section 6 we discuss an alternate approach that we will try in the future.

Finally, we note that we have employed several other recruitment strategies beyond targeted mailings. In particular, we have a partnership with the Milwaukee Public Schools (MPS), through which we visit schools and introduce students to our scholarship opportunity. With the recent birth of several Project Lead The Way (PTLW) engineering-focused curricula at about 20 high schools in Milwaukee - including several in MPS and other schools with high proportions of financially needy, minority, and female students - we plan to focus future recruitment activities to reach students in these programs. 


\section{Selection of Students: Using a Conditional Award Process to Provide Flexibility}

Student selection procedures are designed to act in concert with the recruitment process, but nonetheless constitute a distinct process. One important difference is that unlike the Fall recruitment process, in which students are identified on the basis of ACT Math scores, during the selection process, which occurs in the Spring, students can be evaluated on the basis of actual Placement Test scores. Also, all selection procedures evaluate students independently of race and gender.

The recruitment process informed the selection process in one direct way. As we learned more about disparities between white and minority students on standardized tests, we gradually relaxed and then entirely removed (beginning with the recruitment of the third cohort) eligibility requirements based on minimum Math ACT scores. In the third cohort, this enabled one student to enter the program who would have been excluded by previous years' standards. We also note our that the Director of Diversity in CEAS advised us that imposing a minimum Math ACT standard might discourage applications from underrepresented minority students, even among students who actually meet our originally intended requirements.

Given our understanding of the sizable gap in ACT performance between white students and students of color, we inferred that a similar situation exists with the Placement Test. We were concerned that if reaching calculus placement were imposed as a strict criterion, rather than as a guideline, we would exclude talented minority students who could ultimately be successful in our program. We therefore developed a "conditional award" process in which students who tested at the pre-calculus level (College Algebra or Trigonometry) could be given an award on the condition that they make a credible attempt to become calculus-ready prior to matriculation in the Fall; this can be done by retaking the placement test and/or taking summer coursework.

Table 3 provides a summary of the profile of CSEMS applicants and awardees. The data includes averages for ACT Math scores, high school rank, Expected Family Contribution, calculus placement at time of matriculation, and completion of the two years of the CSEMS Program. The data is broken down by CSEMS admissions status (conditional award or regular award) and by underrepresented status (minority and female).

\begin{tabular}{|c|c|c|c|c|c|c|c|c|c|c|c|c|c|c|c|c|}
\hline \multirow[b]{2}{*}{ Cohort } & \multicolumn{4}{|c|}{ Applicants Denied } & \multicolumn{4}{|c|}{ Awardees Not Matriculating } & \multicolumn{4}{|c|}{ Awardees Matriculating } & \multicolumn{2}{|c|}{$\begin{array}{c}\text { Calc PI @ } \\
\text { Matriculation }\end{array}$} & \multicolumn{2}{|c|}{$\begin{array}{c}\text { Completed } \\
\text { CSEMS }\end{array}$} \\
\hline & $\mathrm{N}$ & ACT & $\mathrm{HS} \%$ & EFO & $\mathrm{N}$ & ACT & $\mathrm{HS} \%$ & EFC & $\mathrm{N}$ & ACT & $H S \%$ & EFC & $\mathrm{N}$ & $\%$ & $\mathrm{~N}$ & $\%$ \\
\hline Tot CSEMS & 77 & 25.7 & 69 & 16781 & 12 & 28.3 & 83 & 4946 & 64 & 28.3 & 83 & 8237 & 62 & 97 & 44 & 69 \\
\hline Reg & 28 & 27.9 & 74 & 21256 & 6 & 26.2 & 79 & 5922 & 47 & 28.9 & 84 & 8581 & 47 & 100 & 32 & 6 \\
\hline Cond & 49 & 24.4 & 64 & 14096 & 6 & 24.9 & 89 & 3770 & 17 & 26.7 & 80 & 7247 & 15 & 88 & 12 & 71 \\
\hline URM & 13 & 23.3 & 76 & 12437 & 2 & 22.0 & 99 & 2491 & 9 & 26.2 & 86 & 4267 & 9 & 100 & & 4 \\
\hline Fem & 10 & 25.5 & 76 & 14320 & 2 & 24.5 & 86 & 4950 & 8 & 27.8 & 92 & 7817 & 8 & 100 & 6 & 7 \\
\hline JRM-Cond & 10 & 22.8 & 63 & 12520 & 2 & 22.0 & 99 & 2491 & 2 & 24.5 & 81 & 2327 & 2 & 100 & 2 & 100 \\
\hline Fem-Cond & 6 & 24.5 & 75 & 12327 & 2 & 24.5 & 86 & 4950 & 2 & 26.0 & 94 & 9926 & 2 & 100 & 2 & 10 \\
\hline
\end{tabular}

Reg $=$ regular status (calculus-placed at time of application); Cond $=$ conditional status (not calculus-placed at time of application); URM = underrepresented minority; Fem = female; ACT = ACT-Math; HS\% = high school class rank; EFC = Expected Family Contribution. 
The data show that overall, of 64 students who entered the Program (aggregate of all four cohorts), 17 were given conditional awards; 15 of these students $(88.2 \%)$ earned calculus placement prior to matriculation, meaning that essentially all students who enter the program begin their coursework at the calculus level. This is striking, since as noted in Sections 1 and 2, only about $30 \%$ of all entering freshmen in the targeted disciplines matriculate with calculus placement. Furthermore, there was essentially no difference in ability of conditional awardees to achieve calculus placement based on gender or ethnicity.

The data also reveal that the conditional award process is significant in recruiting underrepresented minorities and females. Whereas 30.3\% (23/76) of all awardees are conditional awardees, $36.3 \%$ (4/11) of underrepresented minority awardees and $40.0 \%$ (4/10) of female awardees are conditional awardees. The effect is less pronounced for students who actually accepted the awards; $21.8 \%$ (14/64) of all students who accepted awards were conditional awardees, and 22.2\% (2/9) of underrepresented minorities and 25.0\% (2/8) of females who accepted awards were conditional awardees.

Table 3 also indicates that conditional awardees were as successful (71\%) as regular awardees $(68 \%)$ in completing the 2 years of the CSEMS Program. Female students were also successful by this measure $(75 \%)$. These rates are significantly higher than the overall 2-year retention rate in CEAS, which, as reported in Section 2, is about 45\%. We recognize the need to address the lower retention of underrepresented minority students (44\%), although it is interesting that all female and underrepresented minority conditional awardees completed the CSEMS Program. In Section 5, we show that conditional awardees overall are projected to graduate at a lower rate than regular awardees.

We note that we offered occasional financial support, when possible, to cover expenses for summer courses for conditional awardees. We discovered that the scholarship itself serves as a strong incentive for students to attempt improvement in math. To provide further incentive for students to initiate remediation immediately, the Program requires all students to enroll in Calculus III by Fall of sophomore year. Finally, we begin mentoring the conditional awardees by phoning them and helping them to choose the option that is best. In contrast, few pre-calculus level freshmen in the general population choose to attempt improvement over the summer, even though they are actively encouraged.

\section{Retention and Other Student Performance Data}

The ultimate goal of the CSEMS Program, of course, is to foster graduations of students in the targeted disciplines. As the first cohort of CSEMS freshmen was admitted in Fall 2003, it is not yet possible for us to report actual graduation data. However, in Table 4, we provide meaningful estimates of graduation rates of our entering freshmen (1) in the targeted disciplines at UWM, (2) in the targeted disciplines at UWM or elsewhere, and (3) in any discipline at UWM. These estimates are based on careful assessment of each participant's individual academic and enrollment record to date.

In order to demonstrate the impact of the CSEMS Program, in Table 4 we also provide graduation data for CEAS students of comparable profile ${ }^{5}$. The CEAS comparison group was 
extracted from the freshman cohort entering Fall 1999 to have similar ACT Math scores and high school rank as the CSEMS freshman awardees (as reported in Table 3). The comparison group consists of 68 students, comprised of two groups: (1) 30 students similar to regular awardees, with average ACT Math 29.1 and high school rank 81.4\%; and (2) 38 students similar to conditional awardees, with average ACT Math 26.2 and high school rank 80.9\%.

\begin{tabular}{|c|c|c|c|c|c|c|c|c|c|c|c|c|c|c|}
\hline \multirow[b]{2}{*}{ Cohort } & \multicolumn{8}{|c|}{ Fall and Spring Enrollments by Year } & \multicolumn{2}{|c|}{$\begin{array}{c}\text { UWM/Targeted } \\
\text { Disciplines }\end{array}$} & \multicolumn{2}{|c|}{$\begin{array}{c}\text { Targeted } \\
\text { Disciplines }\end{array}$} & \multicolumn{2}{|c|}{$\begin{array}{l}\text { UWM/Any } \\
\text { Discipline }\end{array}$} \\
\hline & F1 & S1 & $\mathrm{F} 2$ & S2 & F3 & S3 & F4 & S4 & $\begin{array}{l}\text { Est } \\
\text { Deg }\end{array}$ & $\%$ & $\begin{array}{l}\text { Est } \\
\text { Deg }\end{array}$ & $\%$ & $\begin{array}{r}\text { Est } \\
\text { Deg }\end{array}$ & $\%$ \\
\hline Fall 2003 & 12 & 12 & 9 & 9 & 8 & 8 & 7 & 7 & 7 & 58.3 & 8 & 66.7 & 9 & 75.0 \\
\hline Reg & 6 & 6 & 4 & 4 & 4 & 4 & 4 & 4 & 4 & 66.7 & 4 & 66.7 & 6 & 100.0 \\
\hline Cond & 6 & 6 & 5 & 5 & 4 & 4 & 3 & 3 & 3 & 50.0 & 4 & 66.7 & 3 & 50.0 \\
\hline URM & 1 & 1 & 0 & 0 & 0 & 0 & 0 & 0 & 0 & 0.0 & 0 & 0.0 & 0 & 0.0 \\
\hline Fem & 1 & 1 & 1 & 1 & 0 & 0 & 0 & 0 & 0 & 0.0 & 1 & 100.0 & 0 & 0.0 \\
\hline Fall 2004 & 20 & 18 & 15 & 15 & 14 & 14 & & & 13 & 65.0 & 14 & 70.0 & 14 & 70.0 \\
\hline Reg & 15 & 14 & 12 & 12 & 11 & 11 & & & 11 & 73.3 & 12 & 80.0 & 11 & 73.3 \\
\hline Cond & 5 & 4 & 3 & 3 & 3 & 3 & & & 2 & 40.0 & 2 & 40.0 & 3 & 60.0 \\
\hline URM & 3 & 2 & 2 & 2 & 1 & 1 & & & 1 & 33.3 & 2 & 66.7 & 1 & 33.3 \\
\hline Fem & 1 & 1 & 1 & 1 & 1 & 1 & & & 1 & 100.0 & 1 & 100.0 & 1 & 100.0 \\
\hline Fall 2005 & 23 & 20 & 18 & 18 & & & & & 14 & 60.9 & 15 & 65.2 & 17 & 73.9 \\
\hline Reg & 18 & 16 & 14 & 14 & & & & & 11 & 61.1 & 12 & 66.7 & 14 & 77.8 \\
\hline Cond & 5 & 4 & 4 & 4 & & & & & 3 & 60.0 & 3 & 60.0 & 3 & 60.0 \\
\hline URM & 4 & 3 & 3 & 3 & & & & & 3 & 75.0 & 3 & 75.0 & 3 & 75.0 \\
\hline Fem & 4 & 4 & 4 & 4 & & & & & 4 & 100.0 & 4 & 100.0 & 4 & 100.0 \\
\hline Fall 2006 & 9 & 7 & & & & & & & 5.2 & 57.8 & 6.2 & 68.9 & 6.7 & 74.4 \\
\hline Reg & 8 & 6 & & & & & & & 4.7 & 58.8 & 5.7 & 71.3 & 6.2 & 77.5 \\
\hline Cond & 1 & 1 & & & & & & & 0.5 & 50.0 & 0.5 & 50.0 & 0.5 & 50.0 \\
\hline URM & 1 & 1 & & & & & & & 0.3 & 30.0 & 0.3 & 30.0 & 0.5 & 50.0 \\
\hline Fem & 2 & 0 & & & & & & & 0 & 0.0 & 1 & 50.0 & 0 & 0.0 \\
\hline Total CSEMS & 64 & & & & & & & & 39.2 & 61.3 & 43.2 & 67.5 & 46.7 & 73.0 \\
\hline Reg & 47 & & & & & & & & 30.7 & 65.3 & 33.7 & 71.7 & 37.2 & 79.1 \\
\hline Cond & 17 & & & & & & & & 8.5 & 50.0 & 9.5 & 55.9 & 9.5 & 55.9 \\
\hline URM & 9 & & & & & & & & 4.3 & 47.8 & 5.3 & 58.9 & 4.5 & 50.0 \\
\hline Fem & 8 & & & & & & & & 5 & 62.5 & 7 & 87.5 & 5 & 62.5 \\
\hline CEAS Comp 5 & 68 & & & & & & & & 36 & 52.9 & & & 46 & 67.6 \\
\hline Reg & 30 & & & & & & & & 15 & 50.0 & & & 18 & 60.0 \\
\hline Cond & 38 & & & & & & & & 21 & 55.3 & & & 28 & 73.7 \\
\hline URM & 6 & & & & & & & & 3 & 50.0 & & & 4 & 66.7 \\
\hline Fem & 7 & & & & & & & & 6 & 85.7 & & & 7 & 100.0 \\
\hline
\end{tabular}

CEAS Comp = CEAS comparison group; Reg = regular awardee (or student from CEAS Comp with similar profile); Cond $=$ conditional awardee (or student from CEAS Comp with similar profile). Blank space $=$ n/a. 
As indicated in Table 4, we project that all 7 currently enrolled students from the Fall 2003 cohort and 13/14 currently enrolled students from the Fall 2004 cohort will graduate. Projections from the Fall 2005 and Fall 2006 cohorts are more speculative; they are reasonable in that they account for further attrition based on students' academic performance to date and prior trends identified in the earlier cohorts (fractional estimates for individual students are included in the analysis of the Fall 2006 cohort). These estimates are also credible because CSEMS students as demanded by the Program - must begin and complete all fundamental coursework in sequence, and CSEMS students have otherwise demonstrated high academic achievement in general. For example, the aggregate average GPA earned by all students successfully completing or continuing the CSEMS Program $\mathrm{s}$ is 3.35 . This corresponds to the top tier of CEAS graduates as measured by time to graduation, i.e. the average GPA of CEAS students graduating in less than 5 (6) years is $3.40(3.16)$, and these students constitute $13 \%(47 \%)$ of the graduates from the entering freshman cohort ${ }^{1}$.

Overall, we estimate that $61.3 \%$ of all freshmen entering the CSEMS Program, including 4 students who did not receive all four semesters of CSEMS funding, will graduate from UWM with a degree in one of the targeted disciplines. In particular, $65.3 \%$ and $50.0 \%$ of regular and conditional awardees, respectively, are anticipated to graduate. Somewhat greater proportions of freshmen are expected to graduate with a degree in one of these disciplines from any institution $(67.5 \%$, reflecting the fact that 4 students left in good standing) and from any discipline at UWM (73.0\%, reflecting the fact that 4 students have already changed majors out of the targeted disciplines, and we estimate that about 3 others will do likewise). For comparison, the overall graduation rate derived of entering freshman in CEAS is about $30 \%{ }^{4}$, and is $52.9 \%$ for the comparison group (50.0\% for those initially enrolling in Calculus I or higher, and $55.3 \%$ for those initially enrolling in College Algebra or Trigonometry).

Thus, it is clear that the CSEMS Program has a positive effect on retention and graduation, even when compared with performance of students of similar profile. We suspect that a key reason for this is that the CSEMS Program requires students to not only to achieve minimum grade standards (e.g. earn at least a $\mathrm{C}$ in each course), but also to take key courses in sequence. The backbone of the CSEMS required course sequence is that all students enroll in Calculus III by third semester (Fall of sophomore year), regardless of their initial math placement. Other benchmarks are specified on a discipline-specific basis. We note that 40 of $55(72.7 \%)$ freshmen from the first three CSEMS cohorts enrolled in Calculus IV by fourth semester, whereas only $9 / 68(13.2 \%)$ of freshmen from the comparison group achieved this ${ }^{5}$.

With respect to diversity, we estimate that $47.8 \%$ of underrepresented minorities and $62.5 \%$ of females who entered the CSEMS Program as freshmen will graduate from UWM with a degree in one of the targeted disciplines. This is comparable to the graduation rates for the underrepresented minorities in the comparison group (50.0\%), but appreciably lower than for females in the comparison group $(85.7 \%)$.

\section{Conclusions and Discussion}

Overall, the recruitment and selection strategies that we have developed are effective in attracting students who are academically talented, financially needy, and diverse. In particular, 
we developed a conditional award process that enables talented students with math placement somewhat below calculus to competitively apply for and attain scholarships. This process provides flexibility to provide opportunities for talented underrepresented minority students, whose average test scores are typically lower than those of white students.

We demonstrated that the CSEMS students are as diverse as the overall population of new students in the targeted disciplines, but much more diverse when compared to students of similar academic and financial profile. We also demonstrated that students entering the CSEMS Program are nearly $100 \%$ calculus-ready, and that their 1-year and 2-year retention rates are much higher than the ambient rates for all students entering the targeted disciplines. We project that students in the CSEMS Program will graduate at a much higher rate $(61.3 \%)$ than the average student in the targeted disciplines, and at an appreciably higher rate than students with similar academic profile $(52.9 \%)$. However, in the future, we seek to foster even greater overall retention rates, especially for underrepresented minorities. We also must address the high attrition of underrepresented minorities that occurred in our Program.

We propose several ways to address these issues in the future. First, we intend to attract even greater proportions of underrepresented minority and female students. We plan to achieve this by forging working relationships with local Project Lead The Way high schools in Milwaukee. These schools represent well over 1000 students who are exposed to pre-engineering curricula, many of whom are female, minority, and financially needy. An excellent overview of PTLW, including its potential to foster diversity, is provided by Reid and Feldhaus ${ }^{3}$.

In our early recruitment activities, our strategy of mailing information to non-white students with ACT Math scores 24-27 (with no such restriction for students with ACT Math scores 28 and higher) appeared to be useful in attracting underrepresented minority students. However, we plan to eliminate this procedure because it does not appear to be universally supported by educators and campus administrators. Instead, we plan to apply a lower income threshold to students with Math ACT scores of 24-27. In addition, we will expand our target regions to include Chicago/Northeast Illinois and the Twin Cities region of Minnesota (because of reciprocal tuition between Wisconsin and Minnesota, and a special scholarship for Illinois residents at UWM, applicants from these states will not be at financial disadvantage compared to peer applicants from Wisconsin). We recently studied results from an internal data request ${ }^{9}$ to provide an estimated profile of students that this approach will reach over 1300 students, nearly 400 of whom $(30 \%)$ are underrepresented minorities. We note that including both the lower income segment, as well as the segments in Illinois and Minnesota, provide gains in proportions of underrepresented minority students in our overall recruitment pool.

We also see an opportunity to link recruitment efforts with placement test preparation. Our experience suggests that applicants do not seriously consider preparing for the placement test until shortly before it is administered in the Spring. We will try to help scholarship applicants prepare for this test as part of their application procedure, by providing a web address for a sample test in our application materials. In addition, when we meet with local high school students, we will offer them opportunities to take a sample test and discuss their results with us. We believe that early notice of the placement test, plus our encouragement to prepare, will enable all students, and underrepresented minorities in particular, to become more competitive. 
Finally, we also plan to provide peer mentors and industry mentors, as well as a living-learning community in one of the campus dormitories. This will foster socialization and create a supportive student-centered environment.

As Bevlee Watford has observed, "[t]he freshman-to-sophomore transition is critical. The majority of drop-outs among engineering undergraduates occur at this stage, but most students who make a successful transition to sophomore year will graduate." ${ }^{2}$ Freshman programs will always bear some institutional risk, as attrition inevitably will occur. However, based on our initial progress and our future plans to address specific program needs, we are convinced that continuing a freshman scholarship program is the strategy that will best serve students in the targeted disciplines at our institution, and advance the College's mission ${ }^{6}$. By coupling the financial support with meaningful student support structures, we will be able to deliver significant gains in retention and graduations in the targeted disciplines.

\section{Endnotes}

[1] The vast majority (over 90\%) of CEAS students participate in co-op employment or internships; such work constitutes approximately 1 year of the 6.8 year total.

[2] Demographic breakdowns (gender, ethnicity) are not available for "entering freshmen" as an isolated subset.

[3] 2-year retention data is taken from a query in November 2001; this data is no longer readily available.

\section{Bibliography}

1. Buechler, Dale N. "Investigating the Mathematical Background of Engineering Graduates to Improve Student Retention." 2004 ASEE North Midwest Regional Conference, Milwaukee, WI, October 2004.

2. REMOVED

3. Loftus, Margaret. "Lending a Hand." ASEE Prism, January 2005.

4. REMOVED

5. REMOVED

6. Reid, Kenneth and Charles Feldhaus. "Articulation Agreements with High Schools Implementing Project Lead The Way." Proceedings of the 2005 ASEE Annual Conference \& Exposition.

7. University of Wisconsin-Milwaukee, College of Engineering and Applied Science, Internal Data Request, September 2006.

8. University of Wisconsin-Milwaukee, College of Engineering and Applied Science, Internal Data Request, January 2007.

9. University of Wisconsin-Milwaukee. UWM College of Engineering and Applied Science Mission, Vision, Strategic Goals and Sub-Goals, 2006-08. http://www.uwm.edu/CEAS/assets/CEASStrategicPlan.pdf. Last queried, February 2007.

10. University of Wisconsin-Milwaukee, Office of Assessment \& Institutional Research, Enrollment Data, http://www.uwm.edu/Dept/Acad_Aff/assessment/dataresources.html. Last Queried January 2007.

11. University of Wisconsin-Milwaukee, Office of Financial Aid, Internal Data Request, April 2006.

12. University of Wisconsin-Milwaukee, Office of Recruitment and Outreach, Internal Data Request, October 2006.

13. Wisconsin State Statute 36.25, 1993.

14. Wisconsin Department of Public Instruction, Data Request, January 2004. 